\title{
4-(4,5-Diphenyl-1H-imidazole-2-yl)phenol: Synthesis and Estimation of Nonlinear Optical Properties using Z-Scan Technique and Quantum Mechanical Calculations
}

\author{
Fatemeh Mostaghni \\ Department of Chemistry, Payam Noor University, P.O. BOX 19395-4697 Tehran, Iran \\ *Corresponding author: E-mail: mostaghnif@yahoo.com
}

Received: $10-26-2020$

\begin{abstract}
In this study, 4-(4,5-Diphenyl-1H-imidazole-2-yl) phenol is successfully synthesized, and its nonlinear optical properties (NLO) are investigated both experimentally and theoretically. Theoretical investigations have been done by using TDDFT and B3LYP functional with usual 6-31+G(d,p) basis set. The results of HOMO-LUMO and NBO analysis show the low energy gap, high total dipole moment, and hyperpolarizabilities $(\beta, \gamma)$ as well as the presence of dipolar excited states with relatively significant dipole-moment changes which are linked to the nonlinearity. The z-scan technique confirmed the NLO properties of title compound. The nonlinear absorption coefficient, refractive index, and third-order susceptibility were found to be $4.044 \times 10^{-1} \mathrm{cmW}^{-1}, 2.89 \times 10^{-6} \mathrm{~cm}^{2} \mathrm{~W}^{-1}$ and $2.2627 \times 10^{-6}$ esu, respectively. The negative sign of $\mathrm{n}_{2}$ indicated the occurrence of self-defocusing nonlinearity. The results show that the title compound can been used as potential NLO material.
\end{abstract}

Keywords: Nonlinearity; z-scan technique; hyperpolarizabilities; triaryl imidazoles.

\section{Introduction}

The development of photonic technology, nonlinear optical materials have received widespread attention both from the research as well as industrial point of view. ${ }^{1-3}$ In recent years, many studies have been reported by researchers to find new compounds with high nonlinear optical properties. The essential requirements of suitable photonic materials are their high nonlinearity, fast response time, chemical stability, and ease of molecular design..$^{4-8}$

In this context, $\pi$-conjugated organic materials have received more attention due to their high nonlinearity and fast response times resulting from the ease of polarizability of the extended mobile $\pi$-electron clouds across the molecule. $^{9-13}$

Unlike inorganic materials in which band structure phenomena cause nonlinear phenomena, in organic materials and polymers, these phenomena arise from the transition of an electron from the highest occupied molecular orbital (HOMO) to the lowest unoccupied molecular orbital (LUMO) that caused a transition of the dipole moment from the ground state to the excited state. $^{14-18}$

Different types of organic compounds with extensive conjugated $\pi$ system are expected to exhibit nonlinear optical properties because of $\pi-\pi$ interactions that allow an intramolecular charge transfer (ICT). ${ }^{19-29}$ Moreover, ICT is responsible for the broadening of the absorption spectrum, and the reduction of the optical bandgap. ${ }^{30-32}$

Over the past two decades, small organic molecules have been a subject of increasing research interest for their potential applications in organic electronics. ${ }^{33}$ Furthermore, it was shown that the $\pi$-conjugated bridges based on heterocyclic rings had improved stability relative to other polyenes. $^{34-37}$

Among these, various types of imidazole derivatives have received widespread attention due to their piezoelectric, photochromic, and thermochromic properties. They are widely used in optoelectronics, superconductors, molecular photonics, sensors, and optical data storage devices. ${ }^{37-39}$

In this study, 4-(4,5-Diphenyl-1H-imidazole-2-yl) phenol was synthesized by one-pot three-component syn- 
thesis using $\mathrm{CoFe}_{2} \mathrm{O}_{4}$. Then for the first time, the nonlinear optical properties of this molecule are measured by the Z-scan technique and quantum mechanical methods. The results showed that the title compound could be a good candidate with the potential application in optoelectronic devices.

\section{Experimental}

All chemicals were analytical grade and purchased from Sigma-Aldrich. Deionized water served as reacting medium. The melting point was measured by an Electrothermal-9200 melting point apparatus. IR spectra were measured on the FTIR-6300 spectrometer (KBr). ${ }^{1} \mathrm{HNMR}$ spectra were recorded on Bruker ADVANC DRX 400 spectrometer, using DMSO as solvent.

\section{1. Synthesis of 4-(4,5-Diphenyl-1H- imidazole-2-yl) Phenol}

To the solution of benzoin (1 mM), 2-hydroxy benzaldehyde $(1 \mathrm{mM})$, ammonium acetate $(4 \mathrm{mM})$ in ethanol $(10 \mathrm{~mL})$ was added $5 \mathrm{~mol} \% \mathrm{CoFe}_{2} \mathrm{O}_{4}$ nanocatalyst. The mixture was reflux in $50^{\circ} \mathrm{C}$, and the progress of the reaction was controlled by TLC using the mixture eluent (n-Hexane: Ethyl acetate 4:1). After completion of the reaction (30 minutes), the catalyst was separated by an external magnet, and the reaction mixture was allowed to cool. Then the precipitate was collected by filtration, washed with water, and recrystallized using ethanol.

The product (figure 1) was characterized by FTIR and ${ }^{1} \mathrm{H}$ NMR and Mass spectroscopy. Yield 87\%; purity > 96\%; mp: $278{ }^{\circ} \mathrm{C}\left(275-276^{\circ} \mathrm{C}\right) .{ }^{40}$

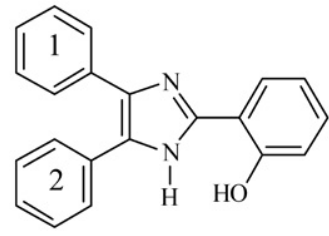

Figure 1. Molecular structure of 4-(4,5-Diphenyl-1H- imidazole-2-yl) phenol

IR $\left(\mathrm{KBr}, \mathrm{cm}^{-1}\right): v / \mathrm{cm}^{-1}: 3598,3445,2996,2468$, 1643, 1613, 1546, 1506, 1490, 1240, 764, 698, ${ }^{1} \mathrm{H}$ NMR: $\delta_{\mathrm{H}}(\mathrm{ppm})\left(300 \mathrm{MHz}, \mathrm{CDCl}_{3}\right): 8.03(\mathrm{~s}, 1 \mathrm{H}, \mathrm{NH}), 7.63-7.66$ (m, 2H), 7.43-7.45 (m, 2H), 7.22-7.26 (m, 4H), 7.07-7.09 (d, 2H), 6.77-6.86 (m, 4H), GC-MS (IE, $70 \mathrm{eV}) \mathrm{m} / z(\%)$ $312(\mathrm{M}+, 100.0), 208,165,89,77,51,41$.

\section{2. UV-Vis Absorption Spectrum}

The UV-Vis absorption spectrum of the sample was recorded using a spectrometer (Jenway model 6310). The

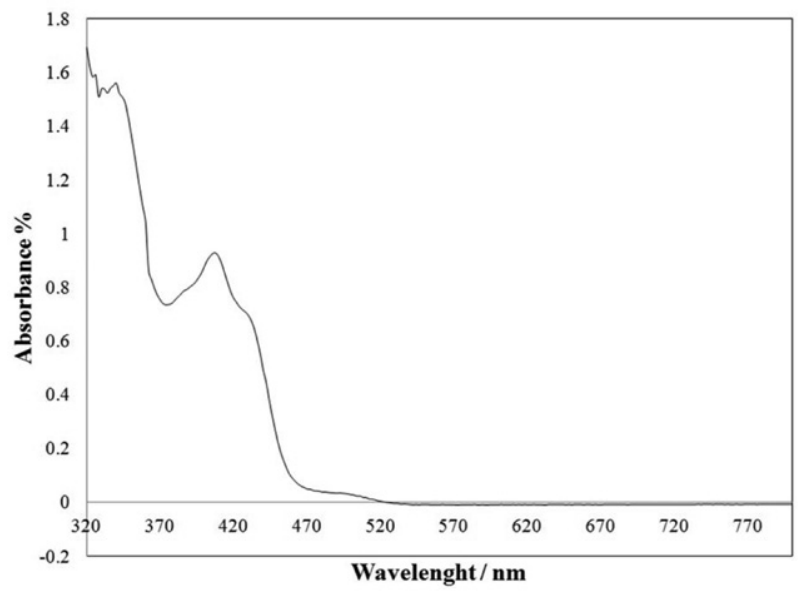

Figure 2. UV-Vis absorption spectra of 4-(4,5-Diphenyl-1H- imidazole-2-yl) phenol

sample was dissolved in DMF and measured in quartz cell in the range of 320 to $1000 \mathrm{~nm}$ (Figure 2). The spectrum showed absorption peaks at $340 \mathrm{~nm}$, and $406 \mathrm{~nm}$.

\subsection{Z-Scan Measurement}

The determining of the third-order nonlinear optical properties of the sample was carried out using the $\mathrm{z}$-scan technique as a standard method. In this method, a very thin sample of matter is exposed to a laser beam while the sample was translated across the focal zone along the $\mathrm{z}$-axis. The light passing through the sample is recorded as a function of the sample position relative to the beam focal point. The Z-Scan method is used to determine the nonlinear refractive index and absorption coefficient in close and open aperture configurations, respectively.

\section{4. Computational Method}

I performed density functional theory (DFT) and time-dependent DFT (TD-DFT) calculations on the title compound using the Gaussian 09 suite of software. ${ }^{41}$ The calculations were carried out by using TD-DFT and B3LYP functional. ${ }^{42,43}$ The usual $6-31 \mathrm{G}+(\mathrm{d}, \mathrm{p})$ basis set was employed in the calculations. Numerous quantities including molecular structures, ionization potentials, electronegativity, HOMO-LUMO energies, and the HOMO-LUMO energy gap, dipole moments, polarizability, and hyperpolarizability Have been measured and discussed.

\section{Results and Discussion}

\section{1. UV-Vis Absorption Spectrum}

As can be seen in Figure 2, this sample has shown the absorption bands in the UV-Vis region between 340-470 $\mathrm{nm}$. The absorption observed at $406 \mathrm{~nm}$ due to the $\pi \rightarrow \pi^{*}$ transition. The wide transparency of the sample in the vis- 
ible region enables it for the second harmonic generation that required for all NLO materials.

The band gap energy was determined using the Tauc relation. ${ }^{44}$ The band gap value obtained using the direct transition. Extrapolating the linear part of the curves to the $\mathrm{X}$ axis yield the bandgap equal to $2.54 \mathrm{eV}$ (Figure 3).

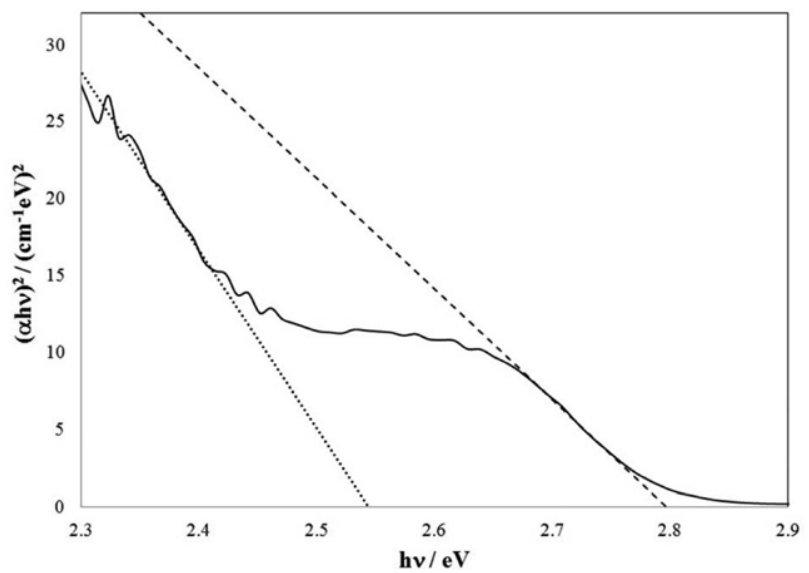

Figure 3. Plot $(\alpha h v)^{2}$ vs. photon energy

\section{2. Nonlinear Absorption Coefficient}

The nonlinear absorption coefficient, the nonlinear susceptibility, and imaginary part of $\chi^{(3)}$ were determined from open aperture $\mathrm{z}$-scan data. For this purpose, the normalized transmittance of open aperture Z-scan at wavelengths $532 \mathrm{~nm}$ was plotted as a function of sample position (Figure 4).

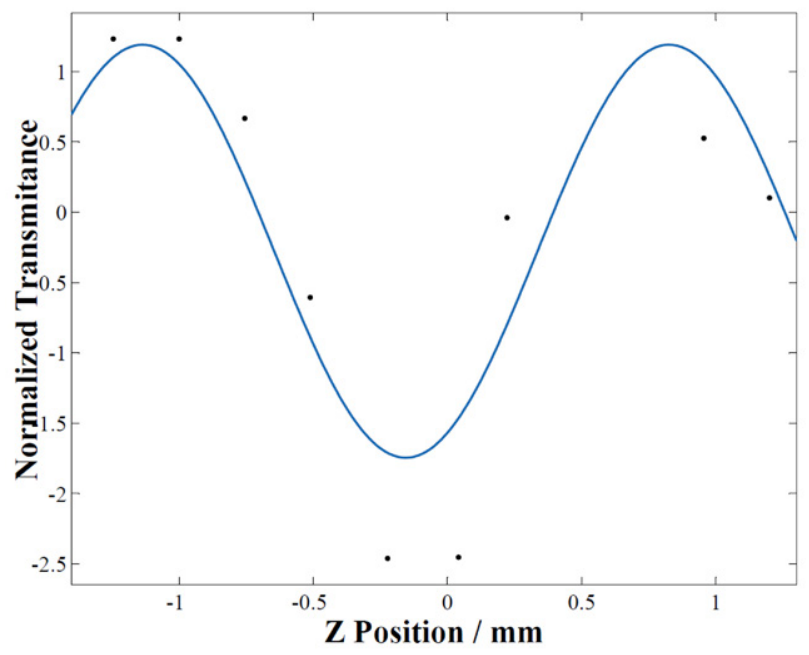

Figure 4. Open aperture Z-Scan data for 4-(4,5-Diphenyl- 1H-imidazole-2-yl) phenol solution.

As can be seen from Figure 4, the curve shows a valley shape, indicating a positive nonlinear absorption coefficient resulting from the two-photon absorptions (TPA) whereby a molecule simultaneously absorbs two photons that are inherently weak at low intensities of light.

The nonlinear absorption coefficient $\beta$ was calculated by the following equations: ${ }^{45}$

$$
\begin{aligned}
& T(z, s=1)=\sum_{m=0}^{\infty} \frac{\left[\frac{\beta I_{o} L_{e f f}}{1+\left(\frac{Z}{Z_{0}}\right)^{2}}\right]^{m}}{(m+1)^{\frac{3}{2}}} \\
& Z_{0}=\frac{K \omega_{0}^{2}}{2} \\
& L_{e f f}=\frac{[1-\exp (-\alpha L)]}{\alpha} \\
& \alpha=-\frac{1}{L} \ln \left(\frac{P}{P_{0}}\right)
\end{aligned}
$$

Where $I_{0}$ is peak on-axis irradiation at the focal point, $\mathrm{Z}$ is the sample position at the minimum transmittance, $Z_{0}$ is diffraction length, $T$ is the total transmittance, $L_{\text {eff }}$ is the effective thickness of the sample and $\beta$ is NLA coefficient. The nonlinear absorption coefficient is tabulated in table 1.

\section{3. Nonlinear Refractive Index}

The sign and magnitude of the nonlinear refractive index, and real part of $\chi(3)$ were determined from the closed aperture $\mathrm{z}$-scan data. The normalized transmittance of the sample as a function of distance from the focus point is plotted in Figure 5.

As figure 5 shows a peak-valley configuration, the nonlinear refractive index is negative and indicates self defocusing nonlinearity.

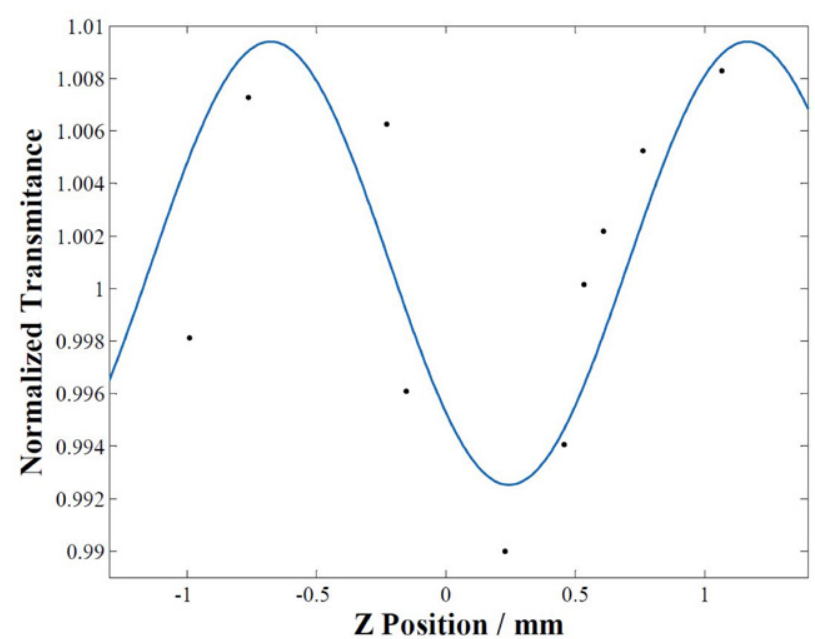

Figure 5. Closed aperture Z-Scan data for 4-(4,5-Diphenyl- 1H-imidazole-2-yl) phenol solution 
However, $\Delta \mathrm{T}_{\mathrm{p}-\mathrm{v}}$ is related to the nonlinear refractive index $n_{2}$ by the following equations: ${ }^{46}$

$$
\begin{aligned}
& \Delta T_{p-v}=0.406(1-S)^{0.27}\left(\frac{2 \pi}{\lambda}\right) n_{2} I_{0} L_{e f f} \\
& I_{0}=\frac{2 p}{\pi \omega^{2}} \\
& S=1-\exp \left(\frac{-2 r_{a}^{2}}{\omega_{a}^{2}}\right)
\end{aligned}
$$

In the above equation, $\Delta \mathrm{T}_{\mathrm{p}-\mathrm{v}}$ is the distance between the peak and valley transmittance which is obtained from figure $5, \mathrm{I}_{0}$ is the intensity in the focused sample, $r_{a}$ is the radius of aperture, $\omega_{\mathrm{a}}$ is the radius of the beam at the aperture, $\mathrm{S}$ is the linear transition, and $\mathrm{n}_{2}$ is the nonlinear refractive index.

Besides, changes in the induction reflectance index were determined by the following equation.

$$
\Delta n=n_{2} I
$$

\section{4. Third Order Susceptibility $\chi^{(3)}$}

The real and imaginary parts of the third-order susceptibility are related to the nonlinear refractive index $n_{2}$ and the nonlinear absorption coefficient $\beta$ respectively.

Where the imaginary part of the third-order susceptibility is calculated from the nonlinear absorption coefficient using the following equation.

$$
\operatorname{Im} \chi^{(3)}(e s u)=\left(\frac{10^{-2} \varepsilon_{0} c^{2} n_{0}^{2} \lambda}{4 \pi^{2}}\right) \beta, \text { in }\left(\frac{c m}{W}\right)
$$

Moreover, the real part of the third order susceptibility can be obtained from the nonlinear refractive index through the relationship:

$$
\operatorname{Re} \chi^{(3)}(e s u)=\left(\frac{10^{-4} \varepsilon_{0} c^{2} n_{0}^{2}}{\pi}\right) n_{2}, \text { in }\left(\frac{c m^{2}}{W}\right)
$$

In the above equations, $\beta$ is the nonlinear absorption coefficient, $\mathrm{n}_{2}$ is the nonlinear refractive index, $\mathrm{n}_{0}$ is the linear refractive index, $c$ is the speed of light in the vacuum and $\varepsilon_{0}$ is the permeability coefficient in the vacuum.

However, the absolute value of nonlinear third-order susceptibility can be obtained by the following equation.
Table 1. Calculated third order nonlinear optical parameters of the title compound

\begin{tabular}{ccccc}
\hline $\begin{array}{c}\mathbf{n}_{2} \times 10^{-6} \\
\mathbf{c m}^{2} / \mathrm{W}\end{array}$ & $\begin{array}{c}\boldsymbol{\beta} \times 10^{-1} \\
\mathbf{c m} / \mathrm{W}\end{array}$ & $\begin{array}{c}\operatorname{Re}\left(\chi^{(3)}\right) \times 10^{-3} \\
\text { esu }\end{array}$ & $\begin{array}{c}\operatorname{Im}\left(\chi^{(3)}\right) \times 10^{-5} \\
\text { esu }\end{array}$ & $\begin{array}{c}\chi^{(3)} \times \mathbf{1 0}^{-6} \\
\mathbf{e s u}\end{array}$ \\
\hline-2.89 & 4.044 & -1.5016 & 8.89 & 2.2627 \\
\hline
\end{tabular}

$\left|\chi^{(3)}\right|=\left\{\left[\operatorname{Re}\left(\chi^{(3)}\right)\right]^{2}+\left[\operatorname{Im}\left(\chi^{(3)}\right)\right]^{2}\right\}^{1 / 2}$

The values of the third-order nonlinear susceptibilitiies obtained for 4-(4,5-Diphenyl-1H-imidazole-2-yl) phenol are listed in table 1.

The high values of negative nonlinear refractive index and the third-order susceptibility of the sample, which are associated with a $2 \mathrm{PA}$ resonance enhancement, indicate that it can be potentially used as an optical limiter to protect tools and human eyes.

\section{5. Electronic Structure and One-Photon Absorption}

Electronic properties such as ionization potential (IP), hardness ( $\eta$ ), softness (S), and electron affinity (EA), can be evaluated from HOMO and LUMO energies. HOMO and LUMO energies, Band gap energy, hardness, softness ionization potential (IP), and electron affinity (EA) are summarized in Table 2.

Quantum mechanical calculations play an important role in the understanding of the relationship between the molecular structure and the nonlinear optical properties of the compounds. There are many factors contribute to enhancing the properties of NLO compounds such as: low bandgap energy, high dipole moment, reversing of groundstate charge distribution and the $\pi$-electronic cloud redistribution via the $\pi$-conjugated system. ${ }^{47}$ In conjugated organic materials, electrons in $\pi$ bond are delocalized and have more motions rather than other electrons. In this case the $\pi$-bond electrons can easily move in the whole molecule space. Increasing the electron charge distribution will result in a larger hyperpolarizability, which is linked to the nonlinearity.

The orbitals involved in the main transitions are shown in figure 6. As can be seen, the HOMO orbital is delocalized over the whole molecule. By contrast, the LUMO is mostly located over two phenyl rings 1 and 2 .

Table 2. Theoretically computed HOMO and LUMO energies, Bond gap energy ( $\left.E_{\text {gap }}\right)$, Hardness ( $\eta$ ), softness (S), Ionization potential (IP), Electron affinity (EA)

\begin{tabular}{ccccccc}
\hline $\begin{array}{c}\mathbf{E}_{\text {HOMO }} \\
\mathbf{e V}\end{array}$ & $\begin{array}{c}\mathbf{E}_{\text {LUMO }} \\
\mathbf{e V}\end{array}$ & $\begin{array}{c}\boldsymbol{\eta} \\
\mathbf{e V}\end{array}$ & $\begin{array}{c}\mathbf{S} \\
\mathbf{e V}\end{array}$ & $\begin{array}{c}\mathbf{I P} \\
\mathbf{K J} / \mathbf{m o l}\end{array}$ & $\begin{array}{c}\mathbf{E A} \\
\mathbf{K J} / \mathbf{m o l}\end{array}$ & $\begin{array}{c}\mathbf{E}_{\text {gap }} \\
\mathbf{e V}\end{array}$ \\
\hline-4.9980 & -1.8098 & 1.594 & 0.314 & 482.225 & 174.622 & 3.18 \\
\hline
\end{tabular}




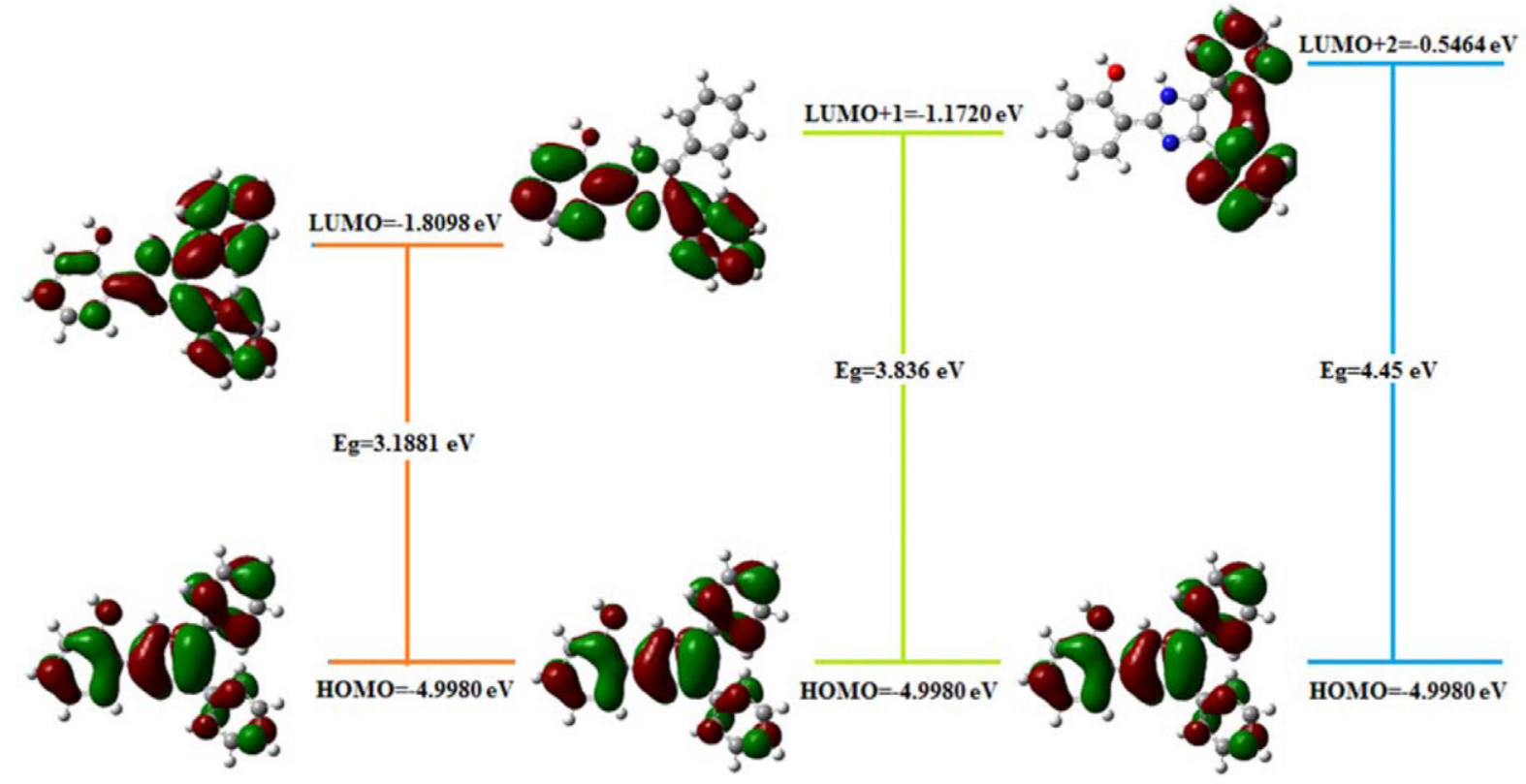

Figure 6. Frontier orbitals of 4-(4,5-Diphenyl-1H-imidazole-2-yl) phenol

Moreover, LUMO+1 is based more on the phenyl ring 2 and phenolic ring while, $\mathrm{LUMO}+2$ is mostly delocalized on the two phenyl rings. Consequently, electron transition from ground to excited states facilitate an electron density transfer.

The short-circuit current density is an important component of the photoelectric conversion efficiency (PCE) is determined by the light-harvesting efficiency (LHE).

The light-harvesting efficiency (LHE) was approximately calculated from oscillator strength (f) using the following equation: ${ }^{48}$

$$
L H E=1-10^{-f}
$$

As can be seen from table 3, both $\mathrm{H} \rightarrow \mathrm{L}$ and $\mathrm{H} \rightarrow \mathrm{L}+1$ transitions dominantly dictate the electronic absorption profile of the studied molecule with sufficiently high $\mathrm{f}$-values. However, the value of excitation energy related to $\mathrm{H} \rightarrow \mathrm{L}$ transition is comparable to the band gap value obtained from the Tauc equation. By contrast, the oscillator strength value of $\mathrm{H} \rightarrow \mathrm{L}+2$ transition is too low to contribute to the absorption spectra. As expected, the low energy electronic excitations have substantial ICT character.
Both $\mathrm{H} \rightarrow \mathrm{L}$ and $\mathrm{H} \rightarrow \mathrm{L}+1$ transitions with the high LHE will have a high short-circuit current density and so the high photoelectric conversion efficiency.

The partially density of states (PDOS) spectra of the title compound was also obtained using quantum mechanical calculations. According to PDOS spectra diagram (Figure 7), band gap was low which is in good agreement with other results.

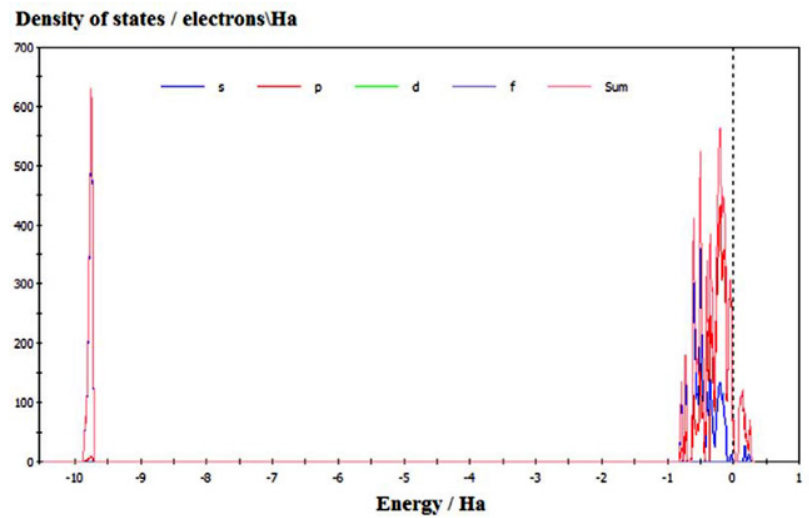

Figure 7. Calculated DOS spectra of 4-(4,5-Diphenyl-1H-imidazole-2-yl) phenol

Table 3. Excitation energies $\left(\mathrm{E}_{\mathrm{ex}}\right)$, oscillator strengths (f), light harvesting efficiencies (LHE), and electronic transitions configurations of the title compound at TD-DFT-B3LYP/6-31+G(d,p) level in DMSO

\begin{tabular}{ccccc}
\hline Excited State & $\mathbf{E}_{\text {ex }}$ & $\mathbf{f}$ & LHE & Transition assignment \\
\hline $82 \rightarrow>83(\mathrm{~S})$ & $2.9654 \mathrm{eV} 418.10 \mathrm{~nm}$ & 0.5678 & 0.7295 & $\mathrm{H} \rightarrow \mathrm{L}(99.18 \%)$ \\
$82 \rightarrow>8(\mathrm{~S})$ & $3.3587 \mathrm{eV} 369.14 \mathrm{~nm}$ & 0.2601 & 0.4506 & $\mathrm{H} \rightarrow \mathrm{L}+1(96.24 \%)$ \\
$82 \rightarrow>5(\mathrm{~S})$ & $3.5015 \mathrm{eV} 354.09 \mathrm{~nm}$ & 0.0031 & 0.0071 & $\mathrm{H} \rightarrow \mathrm{L}+2(96.52 \%)$ \\
\hline
\end{tabular}




\section{6. Second-Order Nonlinear Optical (NLO) Response}

The linear isotropic polarizability indicates the capacity of changing the charge density in the system under the influence of an external field. However, the magnitude of the isotropic polarizability $\alpha$ and anisotropy of polarizability $(\Delta \alpha)$ are calculated using the polarization components as follows. ${ }^{49,50}$

$$
\begin{aligned}
& \alpha_{v e}=\frac{1}{3}\left(\alpha_{x x}+\alpha_{y y}+\alpha \alpha_{z z}\right) \\
& \Delta \alpha=\frac{1}{2}\left[\left(\alpha_{x x}-\alpha_{y y}\right)^{2}+\left(\alpha_{x x}-\alpha_{z z}\right)^{2}+\left(\alpha_{y y}-\alpha_{z z}\right)^{2}\right]^{1 / 2}
\end{aligned}
$$

The first hyperpolarizability $(\beta)$, which is studied using second harmonic generation (SHG) is:

$$
\beta_{\mathrm{tot}}=\left[\begin{array}{c}
\left(\beta_{\mathrm{xxx}}+\beta_{\mathrm{xyy}}+\beta_{\mathrm{xzz}}\right)^{2}+\left(\beta_{\mathrm{yyy}}+\beta_{\mathrm{yzz}}+\beta_{\mathrm{yxx}}\right)^{2} \\
+\left(\beta_{\mathrm{zzz}}+\beta_{\mathrm{zxx}}+\beta_{\mathrm{zyy}}\right)^{2}
\end{array}\right]^{1 / 2}
$$

Also, the direction of charge transfer in the title compound was determined by the ratio of $\beta_{\text {vec }}$ and $\beta_{\text {total }}$ using the following equations:

$$
\cos \theta=\frac{\beta_{\mathrm{vec}}}{\beta_{\mathrm{tot}}}
$$

where $\beta_{\text {vec }}$ is the vector component of first hyperpolarizability. ${ }^{51}$

$$
\beta_{\text {vec }}=\frac{\left(\beta_{x} \mu_{x}+\beta_{y} \mu_{y}+\beta_{z} \mu_{z}\right)}{\mu}
$$

The second hyperpolarizability $(\gamma)$, which is studied using third-harmonic generation (THG) is:

$$
\begin{aligned}
\gamma \equiv & \gamma_{z z z z}=\frac{1}{5}\left[\gamma_{x x x x}+\gamma_{y y y y}+\gamma_{z z z z}+\right. \\
& \left.+\gamma_{z z z z}+2\left(\gamma_{x x y y}+\gamma_{x x z z}+\gamma_{y y z z}\right)\right]
\end{aligned}
$$

The isotropic polarizability $(\alpha)$, the anisotropy of the polarizability $(\Delta \alpha)$, the vector component of the first hyperpolarizability and hyperpolarizabilities $(\beta, \gamma)$ of the title compound are listed in the table 4 .

Table 4 dipole polarizability $(\alpha)$, first and second hyperpolarizability $(\beta, \gamma)$, the vector component of first hyperpolarizability $\left(\beta_{\mathrm{vec}}\right)$ and the anisotropy of the polarizability $(\Delta \alpha)$ of the title compound

\begin{tabular}{ccccc}
\hline $\boldsymbol{\alpha}(\mathbf{a . u})$ & $\boldsymbol{\Delta} \boldsymbol{\alpha}(\mathbf{a . u})$ & $\boldsymbol{\beta}_{\text {total }}(\mathbf{a . u})$ & $\boldsymbol{\beta}_{\text {vec }}$ & $<\boldsymbol{\gamma}>(\mathbf{a . u})$ \\
\hline-128.7264 & 255.5163 & 144.1682 & 133.6176 & -4045.6719 \\
\hline
\end{tabular}

As can be seen, 4-(4,5-Diphenyl-1H-imidazole-2-yl) phenol show the high total static dipole moment and hyperpolarizabilities $(\beta, \gamma)$ which can be attributed to the positive contribution of their conjugation. The ratio of $\beta_{\text {vec }} / \beta_{\text {total }}$ in table 4 is equal to 0.93 , which indicated the unidirectional charge transfer in the title compound. Therefore it is a good candidate for future studies of nonlinear optical properties.

\section{Conclusion}

I have synthesized 4-(4,5-Diphenyl-1H-imidazole-2-yl)phenol as an attractive material for potential application in nonlinear optics. The nonlinear optical properties of the title compound are investigated using the z-scan technique and quantum mechanical calculations. Both theoretical and experimental results reveal that the title compound exhibits large optical nonlinearity. The calculation of the HOMO-LUMO energy gap showed that the eventual charge transfer interactions occure within the molecule. Furthermore, the high value of total static dipole moment and hyperpolarizabilities $(\beta, \gamma)$ were found for the title compound, which was attributed to the positive contribution of their conjugation. The calculated transition dipole moments for ground and excited states indicated an electron density transfer. Besides, the ratio of $\beta_{\mathrm{vec}} /$ $\beta_{\text {total }}$ indicated the unidirectional charge transfer in the title compound. In summary, from all theoretical studies, it was concluded that the title compound can use as potential NLO molecule.

The theoretical results are confirmed by the nonlinear refractive index, and the nonlinear absorption coefficient were determined by $\mathrm{z}$-scan techniques. The magnitude and sign of the nonlinear refractive index $\left(\mathrm{n}_{2}\right)$ determined using close aperture $\mathrm{z}$-scan. $\mathrm{n}_{2}$ was in the range of $10^{-6} \mathrm{~cm}^{2} / \mathrm{W}$. The negative sign of $\mathrm{n}_{2}$ indicated the occurrence of self-defocusing phenomena due to the local variation of the refractive index with temperature. The measured nonlinear absorption coefficient $(\beta)$ by open aperture $\mathrm{z}$-scan was in the range of $10^{-1} \mathrm{~cm} / \mathrm{W}$ associated with the two-photon absorption (TPA) effect. Finally, the physicochemical studies on the title compound revealed the essential property of the title compound for application in the field of nonlinear optic.

\section{Acknowledgments}

The author are grateful to the Payame Noor University for encouragements.

\section{References}

1. M. H. Sadr, V. M. Mohammadi, B. Soltani, K. Jamshidi-Ghaleh, S. Z. Mousavi, Optik. 2016, 127, 6050-6055.

DOI:10.1016/j.ijleo.2016.04.051

2. C. Mallet, G. Savitha, M. Allain, V. Kozmík, J. Svoboda, P. Frère, J. Roncali, J. Org. Chem. 2012, 77, 2041-2046.

DOI:10.1021/jo202412t

3. A. N. Castro, L. R. Almeida, M. M. Anjos, G. R. Oliveira, H. 
B. Napolitano, C. Valverde, B. Baseia, Chem. Phys. Lett. 2016, 653, 122-130. DOI:10.1016/j.cplett.2016.04.070

4. H. S. Nalwa, Handbook of Advanced Electronic and Photonic Materials and Devices, Academic Press, New York, 2001.

5. M. I. Yongsheng, L. Pengxia, Y. Zhou, W. Dong, C. Hui, H. E. Wanli, Y. Huai, Chem. Res. Chin. Univ. 2015, 31, 992-996. DOI:10.1007/s40242-015-5241-9

6. X. H. Zhu, J. Peng, Y. Cao, J. Roncali, Chem. Soc. Rev. 2011, 40, 3509-3524. DOI:10.1039/c1cs15016b

7. S. Yao, H. Y. Ahn, X. Wang, J. Fu, E. W. Van Stryland, D. J. Hagan, K. D. Belfield, J. Org. Chem. 2010, 75, 3965-3974.

DOI:10.1021/jo100554j

8. C. Herbivo, A. Comel, G. Kirsch, A. M. Fonseca, M. Belsley, M. M. Raposo, Dyes Pigments. 2010, 86, 217-226.

DOI:10.1016/j.dyepig.2010.01.006

9. N. Wazzan, Z. Safi, J. Mol. Struct. 2017, 1143, 397-404.

10. A. Pron, P. Gawrys, M. Zagorska, D. Djurado, R. Demadrille, Chem. Soc. Rev. 2010, 39, 2577-632.

DOI:10.1039/b907999h

11. A. Wojciechowski, M. M. Raposo, M. C. Castro, W. Kuznik, I. Fuks-Janczarek, M. Pokladko-Kowar, F. Bureš, J. Mater. Sci. Mater. Electron. 2014, 25, 1745-50.

DOI:10.1007/s10854-014-1793-6

12. A. Mishra, P. Bäuerle, Angew. Chem. Int. Ed. 2012, 51, 202067. DOI:10.1002/anie.201102326

13. S. Ko, E. Verploegen, S. Hong, R. Mondal, E. T. Hoke, M. F. Toney, M. D. McGehee, Z. Bao, J. Am. Chem. Soc. 2011, 133, 16722-5. DOI:10.1021/ja207429s

14. M. Drobizhev, N. S. Makarov, S. E. Tillo, T. E. Hughes, A. Rebane, J. Phys. Chem. B. 2012, 5, 1736-1744. DOI:10.1021/jp211020k

15. M. L. Capobianco, G. Barbarella, A. Manetto, Molecules. 2012, 17, 910-933. DOI:10.3390/molecules 17010910

16. V. Parthasarathy, S. Fery-Forgues, E. Campioli, G. Recher, F. Terenziani, M. Blanchard-Desce, Small. 2011, 7, 3219-3229. DOI:10.1002/smll.201100726

17. T. Wang, X. Wang, J. Zhang, C. Wang, J. Shao, Z. Jiang, Y. Zhang, Dyes Pigments. 2018, 154, 75-81.

DOI:10.1016/j.dyepig.2018.02.031

18. D. Pegu, J. Deb, S. K. Saha, M. K. Paul, U. Sarkar, J. Mol. Struct. 2018, 1160, 167-176. DOI:10.1016/j.molstruc.2018.01.090

19. J. Liu, M. Zhang, W. Gao, A. A. Fedorchuk, I. V. Kityk, J. Mol. Struct. 2018, 1165, 223-227.

DOI:10.1016/j.molstruc.2018.03.133

20. D. Q. Hu, W. J. Wang, R. R. Wang, B. Yang, B.Yu, Chin. J. Chem. Phys. 2015, 28, 645-649.

DOI:10.1063/1674-0068/28/cjcp1502073

21. M. Akram, M. Adeel, M. Khalid, M. N. Tahir, M. U. Khan, M. A. Asghar, M. A. Ullah, M. Iqbal, J. Mol. Struct. 2018, 1160, 129-141. DOI:10.1016/j.molstruc.2018.01.100

22. P. Bragiel, I. Radkowska, R. Belka, B. Marciniak, Z. Bak, J. Mol. Struct. 2018, 1154, 27-38.

DOI:10.1016/j.molstruc.2017.10.017

23. A Kundu, S Karthikeyan, Y Sagara, D Moon, SP.Anthony, ACS Omega. 2019, 4, 5147-5154.

DOI:10.1021/acsomega.8b03099
24. A. A. Kocherzhenko, S. V. Shedge, X. Sosa Vazquez, J. Maat, J. Wilmer, A. F. Tillack, L. E. Johnson, C. M. Isborn, J. Phys. Chem. C, 2019, 123, 13818-13836.

DOI:10.1021/acs.jpcc.8b12445

25. K. Sangeetha, L. G. Prasad, R. Mathammal, J. Mol. Struct. 2018, 1155, 598-609. DOI:10.1016/j.molstruc.2017.11.048

26. A. Szukalski, B. Sahraoui, B. Kulyk, C. A. Lazar, A. M. Manea, J. Mysliwiec, RSC Advances. 2017, 7, 9941-9947.

DOI:10.1039/C6RA26781E

27. P. Han, D. Wang, H. Gao, J. Zhang, Y. Xing, Z. Yang, H. Cao, W. He, Dyes Pigments. 2018, 149, 8-15.

DOI:10.1016/j.dyepig.2017.09.052

28. R. Medishetty, J. K. Zaręba, D. Mayer, M. Samoć, R. A. Fischer, Chem. Soc. Rev. 2017, 46, 4976-5004.

DOI:10.1039/C7CS00162B

29. M. U. Khan, M. Khalid, M. Ibrahim, A. A. C. Braga, M. Safdar, A. A. Al-Saadi, M. R. S. A. Janjua, J. Phys. Chem. C, 2018, 122, 4009-4018. DOI:10.1021/acs.jpcc.7b12293

30. H. Patil, J. Chang, A. Gupta, A. Bilic, J. Wu, P. Sonar, S. V. Molecules. 2015, 20, 17362-17377.

DOI:10.3390/molecules200917362

31. S. S. Fernandes, C. Herbivo, J. Aires-de-Sousa, A. Comel, M. Belsley, M. M. Raposo, Dyes Pigments. 2018, 149, 566-573. DOI:10.1016/j.dyepig.2017.10.001

32. S. B. Katariya, D. Patil, L. Rhyman, I. A. Alswaidan, P. Ramasami, N. Sekar, J. Mol. Struct. 2018, 1150, 493-506.

DOI:10.1016/j.molstruc.2017.08.084

33. E. F. Oliveira, F. C. Lavarda, Mater. Res. 2014, 17, 1369-1374. DOI:10.1590/1516-1439.278814

34. H. Chen, L. Wang, W. Y. Wang, Y. Q. Qiu, H. M. Xie, RSC Advances. 2016, 6, 97063-97069.

DOI:10.1039/C6RA22020G

35. S. M. Afzal, M. A. Razvi, S. A. Khan, O. I. Osman, A. H. Bakry, A. M. Asiri, Plos One. 2016, 11, 1-25.

DOI:10.1371/journal.pone.0161613

36. K. Skonieczny, A. I. Ciuciu, E. M. Nichols, V. Hugues, M. Blanchard-Desce, J. Mater. Chem. 2012, 22, 20649- 20664. DOI:10.1039/c2jm33891b

37. M. R. S. A. Janjua, Inorg. Chem. 2012, 51, 11306-11314. DOI:10.1021/ic3002652

38. J. Kulhánek, F. Bureš, Beilstein J. Org. Chem. 2012, 8, 25-49. DOI:10.3762/bjoc. 8.4

39. M. R. S. A. Janjua, A. Mahmood, M. F. Nazar, Z. Yang, S. Pan, Acta Chim. Slov. 2014, 61, 382-390.

40. M. Amir, I. Ahsan, W. Akhter, S. A. Khan, I. Ali, Indian J. Chem. 2011, 50B, 207-213.

41. M. J. Frisch, G. W. Trucks, H. B. Schlegel, G. E. Scuseria, M. A. Robb, J. R. Cheeseman, G. Scalmani, V. Barone, G. A. Petersson, H. Nakatsuji, X. Li, Gaussian 09, Revision A. 02, Gaussian, Inc., Wallingford, CT, 2016.

42. E. H. Anouar, J. Gierschner, J. L. Duroux, P. Trouillas, Food Chem. 2012, 131, 79-89.

DOI:10.1016/j.foodchem.2011.08.034

43. S. Markovic, J. Tosovic, J. Phys. Chem. A, 2015, 119, 93529362. DOI:10.1021/acs.jpca.5b05129

44. R. Bhatt, I. Bhaumik, S. Ganesamoorthy, A. K. Karnal, M. K. 
Swami, H. S. Patel, P. K. Gupta, Phys. Stat. Sol. (a). 2012, 209, 176-180. DOI:10.1002/pssa.201127361

45. E. W. Van Stryland, M. Sheik-Bahae, Characterization techniques and tabulations for organic nonlinear optical materials, Routledge; 2018. pp. 671-708.

46. J. Jayabharathi, V. Thanikachalam, K. B. Devi, M. V. Perumal, Spect. Chim. Acta Part A, 2012, 86, 69-75.

DOI:10.1016/j.saa.2011.09.067

47. J. Preat, D. Jacquemin, E. A. Perpete, Energy Environ. Sci. 2010, 3, 891-904. DOI:10.1039/c000474j
48. P. Günter, editor. Nonlinear optical effects and materials. 4rd ed. Berlin: Springer; 2012.

49. C. Valverde, S. A. L. Castro, G. R. Vaz, J. L. A. Ferreira, B. Baseia, F. A. P. Osório, Acta Chim. Slov. 2018, 65, 739-749.

DOI:10.17344/acsi.2018.4462

50. Muhammad Ramzan Saeed Ashraf Janjua, Chun-Guan Liu, Wei Guan, Jia Zhuang,

51. S. Muhammad, L. K. Yan, Z. M. Su, J. Phys. Chem. A, 2009, 113, 3576-3587. DOI:10.1021/jp808707q

\section{Povzetek}

V prispevku opisujemo sintezo spojine 4-(4,5-difenil-1H-imidazol-2-il)fenol in eksperimentalne ter teoretične raziskave njenih nelinearnih optičnih lastnosti. Teoretične raziskave so bile izvedene $\mathrm{z}$ uporabo funkcij TD-DFT in B3LYP z običajno nastavitvijo 6-31 ++G(d,p). Rezultati analiz HOMO-LUMO in NBO kažejo nizko vrednost prepovedanega pasu, visok dipolni moment in hiperpolarizabilnost $(\beta, \gamma)$ kot tudi prisotnost dipolarnih vzbujenih stanj z razmeroma visokimi spremembami dipolnega momenta, povezanimi z nelinearnostjo. Metoda z-skeniranja je potrdila NLO lastnosti spojine. Nelinearni absorpcijski koeficient, refrakcijski indeks in susceptibilnost tretjega reda znašajo $4.044 \times 10^{-1} \mathrm{cmW}^{-1}, 2.89 \times$ $10^{-6} \mathrm{~cm}^{2} \mathrm{~W}^{-1}$ in $2.2627 \times 10^{-6}$ esu. Negativna vrednost $\mathrm{n}_{2}$ kaže na samo-defokusiranje in nelinearnost. Rezultati kažejo, da bi spojino lahko uporabljali kot potencialni NLO material.

Except when otherwise noted, articles in this journal are published under the terms and conditions of the Creative Commons Attribution 4.0 International License 